\title{
Research
}

\section{Cumulative Effects of Coastal Habitat Alterations on Fishery Resources: toward Prediction at Regional Scales}

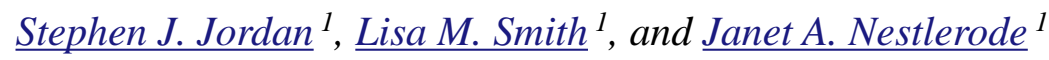

\begin{abstract}
Coastal habitat alterations such as the loss of submersed aquatic vegetation (SAV) and hardening of shorelines could have cumulative effects on valuable fishery resources. To investigate this effect, we developed a multiscale modeling framework for blue crab (Callinectes sapidus) in the northern Gulf of Mexico. Areal coverage of shoreline land cover and SAV for Mobile Bay, Alabama, were combined with information from small-scale biological studies and long-term, large-scale commercial fishery data to model the potential effects of marginal habitat losses on the blue crab fishery. We applied stochastic variation in annual recruitment to the fishery to estimate probabilities for sustainable harvests under scenarios of habitat loss. The simulations suggested that, accumulated over large areas, relatively small local losses of estuarine marsh edge and SAV habitats could have long-term negative effects on the sustainability of the fishery. Spatially extensive models are required to investigate the cumulative ecological effects of many local environmental changes. The requisite scaling adds uncertainty and reduces precision, but if model parameters are accurate at each scale, accurate predictions of long-term outcomes and probabilities are possible.
\end{abstract}

Key Words: Blue crab; Callinectes sapidus; fishery; Gulf of Mexico; habitat; population model

\section{INTRODUCTION}

The integrity of aquatic ecosystems and habitats at the land-sea interface is challenged by several forces, ranging from plot-scale destruction and disturbance to watershed-scale perturbations to global changes in climate and human demographics. The scientific challenge is to model and predict the cumulative effects of these forces on coastal ecosystems and their services to society. The most valuable fisheries are dependent on functional coastal habitats for sustained productivity, but essential relationships between habitat attributes and fish and invertebrate population dynamics are virtually unexplored at the scales required for cumulative impact analysis. Building models that link vital biological rates measured at the patch scale with regional-scale geospatial coverage and longterm fisheries data appears to be a promising approach. Such models could be used to evaluate a wide range of scenarios of cumulative habitat loss, alteration, and restoration for their effects on the sustainability of coastal fisheries. With the addition of economic coefficients or variables, the models could be used in benefit-cost analysis to inform management decisions and policies at local, regional, and national scales. Here, we describe a modeling approach to predicting habitat effects on populations of selected Gulf of Mexico fishery species.

Human population density is increasing rapidly in coastal areas of the United States (Cato and Adams 1999, Scavia et al. 2003). Housing, businesses, and infrastructure are associated with increasing population, as are greater risks of disturbing, destroying, and polluting the coastal habitats essential to sustaining fisheries, wildlife, recreational opportunities, and aesthetic values. Although development in the near-coastal zone has been restrained by a variety of local, state, and federal legislation and permitting requirements, albeit in some regions more than others, the pressure of human uses continues to grow. Even in states that have legislated comprehensive coastal policies such as the California Coastal Act, the Maryland Critical Areas Act, and the Virginia Chesapeake Bay Preservation Act, decisions about whether to permit 
development and other uses typically are made on a case-by-case basis. Often, federal environmental statutes such as the National Environment Policy Act and the Clean Water Act are applied similarly and cannot fully satisfy their policy goals without the support of comprehensive research to understand the cumulative effects of individual activities on coastal ecosystems.

Scientific evidence that multiple small projects, in the aggregate, create large-scale impacts would provide support for more effective application of environmental laws and policies. So long as models are lacking to predict the cumulative effects on fisheries, wildlife, and ecosystems of altering the coastal landscape, these resources will be at risk of "death by 1000 cuts." As examples, one residential dock, a few meters of bulkhead, or dredging a small channel for recreational boating have minimal impacts, but the cumulative effects of thousands of such actions over a region could lead to sustained losses of vulnerable coastal resources.

The coastline of the northern Gulf of Mexico borders five U.S. states: Florida, Alabama, Mississippi, Louisiana, and Texas. All have valuable commercial and recreational fisheries for species such as penaeid shrimp, blue crab, and sciaenid fishes that depend on near-shore coastal habitats during critical phases of their life cycles. This coastline also is facing rapidly increasing population (Cato and Adams 1999) and heavy development pressure, and a general lack of comprehensive policies or legislation to constrain them. Nevertheless, coastal development has not been so intensive or extensive that severe widespread habitat degradation has resulted, so there is an opportunity to evaluate the potential for cumulative effects before they do irreparable damage on a regional scale. The fish and shellfish resources that support the most valuable Gulf of Mexico fisheries are habitat dependent and have region-wide distributions and panmictic populations (McMillen-Jackson et al. 1994, Guillory et al. 1998, 2001). Conceptually, cumulative effects of moderate changes in local habitat conditions could be scaled up to these regional populations (Dantin et al. 2005).

The blue crab (Callinectes sapidus) supports a major commercial fishery in the Gulf of Mexico: from 1980 to 2004, reported hard crab landings in the Gulf averaged $26.8 \times 10^{3}$ tons $\left(24.3 \times 10^{6} \mathrm{~kg}\right)$, with a peak of $35.9 \times 10^{3}$ tons $\left(32.5 \times 10^{6} \mathrm{~kg}\right)$ in 1988. The annual dockside value of this fishery has exceeded US $\$ 40$ million in recent years. In addition, there is substantial recreational catch, estimated at 4-20\% of commercial landings, softshell and peeler crab fisheries (reported landings averaged approximately $0.1 \times 10^{6} \mathrm{~kg}$ ), and by-catch of blue crab in trawl fisheries. Commercial landings, especially the peeler crab component, and by-catch are under-reported in unknown, but probably significant, quantities (Guillory et al. 1998; National Oceanic and Atmospheric Administration Fisheries Service: http://www.st.nmfs.gov/st1/commercial/ landings/annual landings.html).

Field and laboratory studies in Gulf of Mexico and Atlantic coastal environments have shown that early juvenile blue crab has higher population densities and survival rates in vegetated habitats, i.e., marsh edge and seagrass, than in open water, apparently because the physical structure of vegetated habitats supplies refuges that reduce inter- and intraspecific predation (Moksnes et al. 1997, Minello et al. 2003). Eight such studies reviewed by Minello et al. (2003) in the aggregate indicated a $38 \%$ survival advantage for marsh and a $41 \%$ survival advantage for seagrass over open-water habitats. These effects could be critical in the recruitment and population dynamics of the blue crab.

We demonstrate an approach that combines patchscale effects of habitat alteration on recruitment dynamics, the spatial distribution of selected habitat types, and long-term region-wide fishery information to model the cumulative effects of habitat change on the U.S. Gulf of Mexico blue crab fishery. Recruitment dynamics are estimated from published information on population densities and survival rates of early life stages. Our purposes for developing this model were: to produce and test a framework for future multiscale modeling of habitat effects for use in predicting and managing coastal habitats, to identify sources of uncertainty and data gaps to improve the precision and accuracy of predictions, and to demonstrate the potential for large-scale effects of multiple small-scale decisions. 


\section{METHODS}

\section{Mobile Bay recruitment analysis}

A probabilistic survey design for Alabama estuaries was used to establish spatial units for estimating the number of juvenile blue crab expected to recruit to the adult population from the Mobile Bay system, including estuarine tributaries and the Alabama portion of Mississippi Sound (Fig. 1). The area of each polygon represents $\sim 55.2 \mathrm{~km}^{2}$. A hexagonal grid created for the National Coastal Assessment Program (NCA; U.S. Environmental Protection Agency 2005) was used as the spatial delimiter. A land-cover data set was created by merging U.S. Geological Survey National Wetlands Inventory digital habitat distribution data (http://www.fws.gov/ wetlands) with 2002 seagrass distribution data (Barry A. Vittor and Associates, Inc. 2004). Landcover data sets were collapsed into emergent vegetation-marsh edge (ME), soft nonvegetated bottom (SNB), and submerged aquatic vegetation (SAV) and then overlain with the hexagonal sampling grid. This data set was used to produce summed totals by land-cover category for each hexagon; i.e., each hexagon was represented by its total area of ME, SNB, and SAV.

Salinity data for Mobile Bay from the NCA were used to assign each hexagon to a salinity zone: oligohaline, mesohaline, polyhaline, or euhaline. Based on published values for multiple Gulf of Mexico estuaries (Minello 1999), the average estimated density (individuals $/ \mathrm{m}^{2}$ ) of postlarval and juvenile blue crab for each habitat type, within each salinity zone, was used to calculate the number of postlarval and early juvenile individuals expected to be produced within each hexagon. The number of postlarvae and juveniles expected to be produced from each hexagon was then multiplied by the mean survival rates $\left(S_{1}\right)$ for these size classes by habitat type from a compilation of field and laboratory experimental results (Minello et al. 2003). The number of juveniles expected to survive from each hexagon was then multiplied by an estimated proportion of older juveniles surviving sources of natural mortality $\left(S_{2}\right)$ before recruiting to the fishery. We found no explicit estimates of survival rates for larger juvenile blue crab $(>10 \mathrm{~mm}$ carapace width [CW]) in the Gulf of Mexico. Therefore, we used catch per effort (CPE) data by size class from fishery-independent surveys for Alabama (Heath 1998) and Mississippi (Perry et al. 1998) estuaries to estimate $S_{2}$. Heath (1998) reported CPE for 10-
$39 \mathrm{~mm} \mathrm{CW}$ and 40-124 mm CW size classes from seine and beam plankton trawl samples taken from 1985 to 1994 . We computed the mean of $S_{2}$ from the combined sampling gear as $S_{2}=n_{2} / n_{1}$, where $n_{2}$ is CPE for the larger size class and $n_{1}$ is CPE for the smaller size class. Estimates extracted from Perry et al. (1998: their Fig. 13) produced an estimate of $S_{2}$ within the range of the estimates from Heath's (1998) data.

This formulation included two separate nominal life stages, classified by size, for which survival by habitat type $\left(S_{1 i}\right)$ was used for the earlier stage (settled postlarvae and early juveniles) $<10 \mathrm{~mm}$ $\mathrm{CW}$, and $S_{2}$ was the survival for later (pre-recruit) juveniles 10-124 mm CW. Blue crab becomes less dependent on vegetated habitats as it grows (Moksnes et al. 1997), so this two-stage formulation, with habitat-dependent survival applied only to the earlier life stages, was reasonable. The salinity stratification was used only for densities; the sparse information available did not support varying survival rates by salinity zone.

The number of recruits was calculated for each hexagonal cell and then summed over cells to estimate the number of blue crab individuals recruited from the Mobile Bay system to the adult Gulf of Mexico population. The equation for generating recruits to the fishable stock was

$$
R=\sum_{j} \sum_{i}\left(D_{i} \times A_{i j} \times S_{l i} \times S_{2}\right)
$$

where $R$ is the number of recruits, $D$ is the density of juveniles (individuals $\left./ \mathrm{m}^{2}\right), A$ is the area $\left(\mathrm{m}^{2}\right)$, the subscript $i$ denotes the habitat type, and the subscript $j$ denotes the cell (Fig. 2).

Habitat coverages were then manipulated to model the effects of habitat change within each cell and within the Mobile Bay estuary system. The example scenarios included (1) no change, or baseline habitat conditions; (2) 20\% SAV loss within the system across multiple cells; (3) 20\% SAV loss within one cell; and (4) $10 \%$ hardened shoreline (i.e., loss of ME and SNB habitat) within the system (Table 1). 
Fig. 1. Mobile Bay and adjacent Alabama estuaries overlain with a hexagonal grid for estimation of blue crab recruitment from selected habitat types.

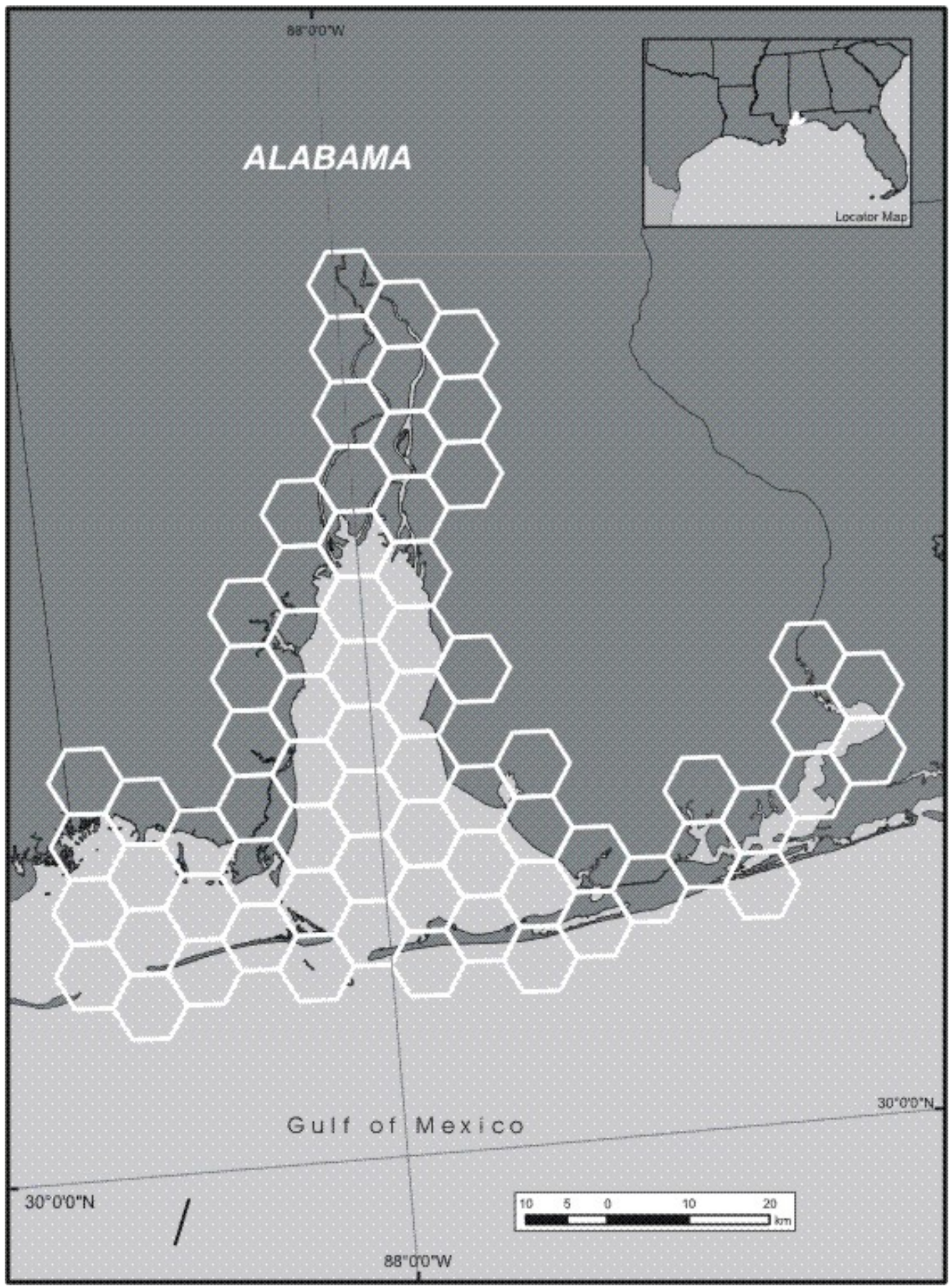


Fig. 2. Schematic diagram of the habitat model for estimating effects of habitat change on the blue crab fishery. $\mathrm{ME}=$ marsh edge; $\mathrm{SAV}=$ submersed aquatic vegetation; $\mathrm{SNB}=$ soft, nonvegetated bottom.

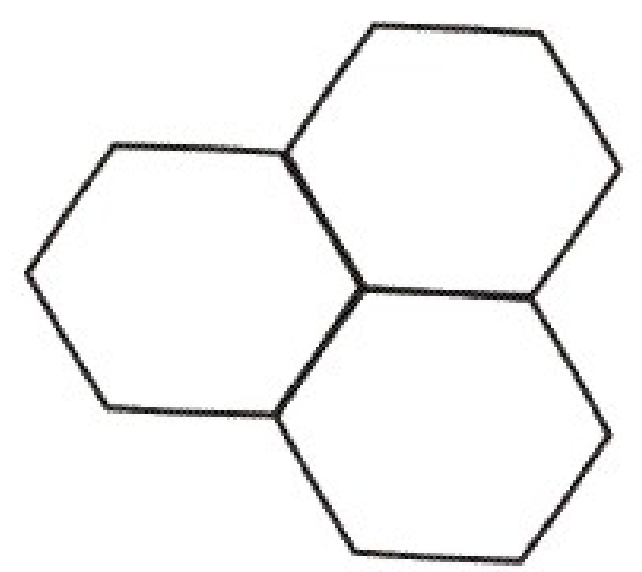

Proportion ME, SAV, SNB

$\mathrm{x}$ area of polygons
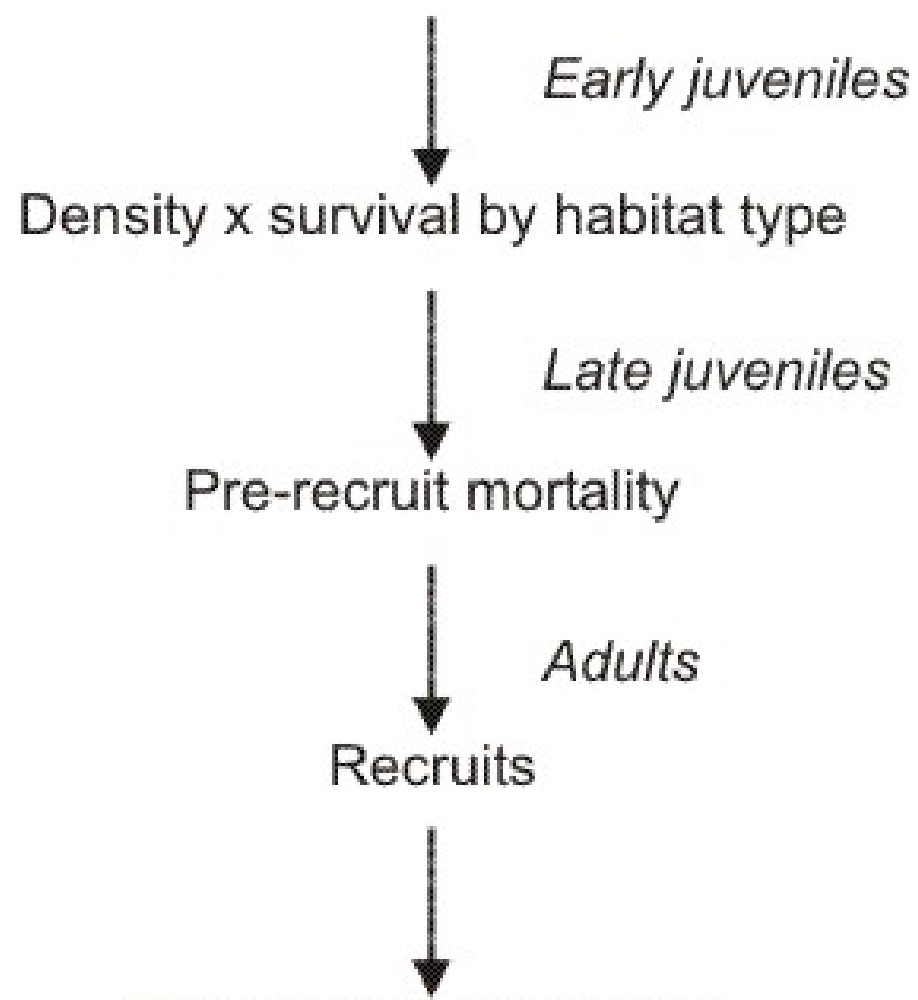

Fishery model 
Table 1. Estimated numbers of juvenile blue crab by habitat type and the resulting numbers of recruits to the adult stock based on habitat scenarios and pre-recruit survival. Cell refers to units of the hexagonal spatial grid overlain on the Mobile Bay system.

\begin{tabular}{lccc}
\hline \hline Habitat scenario & Number of juveniles & Number of recruits & Percent of baseline \\
\hline Baseline $\dagger$ & $1,003,962,457$ & $116,459,645$ & 100 \\
$10 \%$ hardened shoreline $\dagger$ & $966,935,433$ & $112,164,510$ & 96.3 \\
$20 \%$ SAV loss, 3 cells§ & $992,335,955$ & $115,110,971$ & 98.8 \\
$20 \%$ SAV loss, 1 cell! & $999,791,517$ & $115,975,816$ & 99.6 \\
\hline
\end{tabular}

$\dagger$ No change from proportions of habitat types mapped by the U.S. Geological Survey (1988 unpublished data) and Barry A. Vittor and Associates, Inc. (2004).

\$Combination of unvegetated near-shore and marsh edge in proportion to the entire Mobile Bay system (original ratio 9:1 vegetated:unvegetated) in two oligohaline and two polyhaline zones.

$\S$ Losses by cell and salinity zone were distributed as $60 \%$ oligohaline, $25 \%$ polyhaline, and $15 \%$

oligohaline. The total $20 \%$ loss is for the entire Mobile Bay system.

'Oligohaline zone.

\section{Blue crab population model}

A Gulf-wide model of the fishable blue crab stock was generated from a 1950-2004 record of U.S. commercial landings of hard crabs from the five states bordering the Gulf of Mexico (National Oceanic and Atmospheric Administration Fisheries Service: http://www.st.nmfs.gov/st1/commercial/ landings/annual landings.html). Fishery-independent total mortality $(Z)$ data for 1967-1998, derived from state sampling programs using Von Bertalanffy analysis (Guillory et al. 2001, Pellegrin et al. 2001), and commercial CPE data (catch per trap) for 19751992 from Guillory et al. (1998) were used as correlative evidence for the apparent trend in fishing mortality. Although various types of fishing gear were used historically in the crab fishery, virtually all reported landings after 1974 were from traps (Guillory et al. 1998). Annual precipitation data for the Gulf states, obtained from the National Climatic Data Center of the National Oceanic and Atmospheric Administration (http://www.ncdc.noaa. gov/oa/climate/research/cag3/state.html), Mississippi River annual mean and peak flows at Vicksburg, Mississippi (U.S. Geological Survey National Water Information System: http://waterdata.usgs.gov/ nwis/rt), and the frequency and intensity of hurricanes making landfall on the Gulf of Mexico coast (expressed as annual frequency multiplied by Saffir-Simpson category; National Oceanic and Atmospheric Administration's National Weather Service Hurricane Center: http://www.nhc.noaa.gov/ pastprofile.shtml) were used to investigate the influence of long-term environmental variation on recruitment to the fishable blue crab stock.

The fishery model had three parameters: $S_{0}$, the initial stock of fishable hard crabs in tons; $r$, the instantaneous annual rate of population change; and $F$, the instantaneous annual rate of fishing mortality. Annual stock was computed as

$$
S_{t}=S_{t-1} \times e^{r}
$$

where $t$ is time in years. Annual landings $(H)$ were computed as

$$
H_{t}=S_{t} \times\left(1-e^{-F}\right) .
$$


Table 2. Sensitivity of the recruitment model to variation in the density and survival of blue crab early life stages in marsh edge habitat. The first value of $r$ (the rate of population change) was used in simulating a 10\% hardened shoreline scenario. Percentages refer to the actual values used in the model.

\begin{tabular}{lcc}
\hline \hline Density, $D(\%)$ & Survival, $S_{1}(\%)$ & Rate of population change, $r$ \\
\hline 100 & 100 & -0.045 \\
50 & 100 & -0.031 \\
100 & 50 & -0.028 \\
50 & 50 & -0.020 \\
150 & 100 & -0.054 \\
100 & 150 & -0.052 \\
150 & 150 & -0.064 \\
\hline
\end{tabular}

Other population parameters that were derived from available data and model assumptions included a full time-series of instantaneous total mortality $(Z)$ extrapolated from the linear trend in fisheryindependent surveys, instantaneous natural mortality $(M=Z-F)$, and instantaneous gross recruitment $(G=r+Z)$, that is, the exponential proportion of the stock in existence at time $t-1$ that recruited to the stock at time $t$. The $Z, M$, and $G$ parameters were not included in model calculations, but were retained for further investigations. For example, a model with variable $M$ might be used to examine potential effects on the population associated with by-catch or disease.

A long-term increasing trend in landings was modeled using linear regression. We assumed that the linear trend in landings was proportional to increasing fishing mortality over the period of record and that residual (de-trended) landings were proportional to annual recruitment to the fishable stock. Because no explicit information on fishing mortality rates was available, we made reasonable guesses at starting and ending points to generate a linear increasing trend over time in the finite exploitation rate ( $U$, the proportion of the stock harvested), beginning at 0.1 in 1950 and increasing to 0.5 in 2004. From this trend in $U$, we computed instantaneous annual fishing mortality as

$$
F=-\log _{\mathrm{e}}(1-U)
$$

and annual stock size $(S)$ as $H / U$, where $H$ is annual reported landings. Instantaneous annual net recruitment (the rate of change in stock size) to the fishable stock $(r)$ was computed as

$$
r=\log _{\mathrm{e}}\left(S_{t} / S_{t-1}\right) .
$$

For forward simulations (forecasts), the starting values of $S$ and $F$ were taken as the 2004 output from the hindcast simulation. The mean of $F$ was held constant for all forward simulations, whereas mean $r$ varied by scenario. The baseline value of $r$ was computed using Eq. 6. For scenarios of habitat alteration, $r$ was computed from the proportional reduction in recruits for each scenario: 
Table 3. Values of variables and parameters used to simulate blue crab stock and landings in hindcast mode.

\begin{tabular}{lcc}
\hline \hline Variable or parameter & Value (units) & Standard deviation \\
\hline Year & $1950-2004$ & \\
Initial stock & 85,351 (tons) & \\
Rate of population change, $r$ & -0.008 & \\
Instantaneous annual rate of fishing mortality, $F$ & 0.371 & \\
\hline
\end{tabular}

$r_{s}=r_{b}+\log _{\mathrm{e}}\left[1-\left(\right.\right.$ recruits $_{b}-$ recruits $\left._{s}\right) /$ recruits $\left._{b}\right](6)$

where $s$ is the scenario being simulated and $b$ is the baseline value. We assumed that recruitment to the fishable stock was an annual process, i.e., a single cohort of pre-recruits grew from larval settlement to fishable size each year (Guillory et al. 1998), and that habitat effects calculated for the Mobile Bay system would apply proportionally to the Gulf-wide recruitment process.

In all simulations, $r$ was generated as a random variate from a normal distribution defined by the mean and standard deviation of the parameter as estimated from the historical time series. Running the model repeatedly (1000 times for each year of the simulation) with the constrained random variate supported estimates of uncertainty associated with unexplained variation, i.e., annual fluctuations in $r$ derived from the historical time series. To illustrate uncertainty, we computed frequency distributions and summary statistics over the last five years of simulations (2046-2050), along with probabilities that the stock would remain stable through 2050.

\section{RESULTS}

\section{Mobile Bay recruitment analysis}

The densities of newly settled and early juvenile blue crab varied by habitat type and salinity zone. Although the specific densities were derived from a compilation of studies in Texas and Louisiana estuaries (Minello 1999), a review of several other studies, along with published and unpublished primary data for several Gulf of Mexico estuaries, revealed similar patterns of habitat preference and mean density. See especially a study of Mobile Bay by Heck et al. (2001), which indicates the same relative patterns of densities by habitat and salinity that we used in our analysis.

Mean estimates of early life stage survival $\left(S_{1}\right)$ by habitat type from Minello et al. (2003) were 0.50 for SAV, 0.49 for ME, and 0.36 for SNB. The geometric mean of log-normally distributed survival rates for $>10 \mathrm{~mm} \mathrm{CW}$ pre-recruits, estimated from the time-series of seine and trawl catches for Alabama (Heath 1998), was $11.6 \%(95 \%$ confidence limits: 7 and 20\%). Fishery-independent estimates of survival for Mississippi from seine and trawl samples (Perry et al. 1998) ranged from 7 to $16 \%$. Therefore, we used 0.116 as our estimate of $S_{2}$. Total numbers of juvenile blue crab and recruits to the adult stock decreased from the baseline scenario of no habitat change by $1.2 \%$ for the system-wide $20 \%$ SAV loss scenario, by $0.4 \%$ for SAV loss in one cell, and by $3.6 \%$ for the $10 \%$ hardened shoreline scenario (Table 1).

We varied density and $S_{1}$ from 0.5 - to 1.5 -times the model values to examine the sensitivity of the recruitment model to these variables. For this analysis, we concentrated on the hardened shoreline scenario because it generated the largest change in recruitment and hence had the largest effect on the fishery model. Using computed values of $r$ as the response, the model was only moderately sensitive to either variable, but slightly more sensitive to reduced $S_{1}$ than to reduced density. Conversely, it 
Fig. 3. Gulf of Mexico blue crab landings by year and the linear trend. The linear trend was estimated using linear regression: $y=477.8 x-925,213$, where $y$ is the predicted annual landing and $x$ is the year; $\mathrm{R}^{2}=0.84, \mathrm{p}<0.0001$.

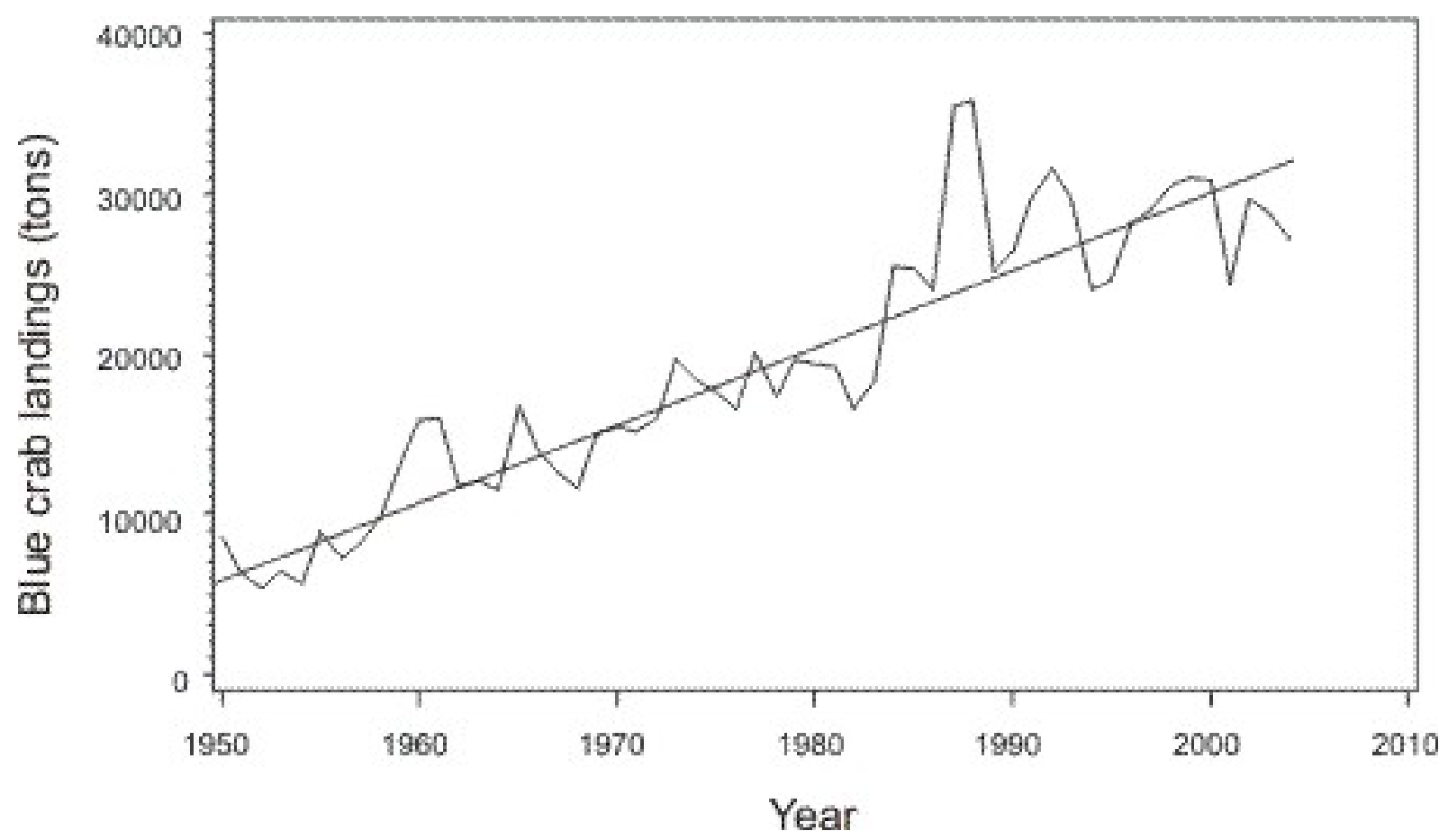

was more sensitive to increased density than increased $S_{1}$ (Table 2).

The recruitment analysis baseline scenario generated $1.16 \times 10^{8}$ recruits of harvestable size from the Mobile Bay system, which contains approximately $14 \%$ of the total area of the U.S. Gulf of Mexico estuaries. A typical harvestable blue crab $(130 \mathrm{~mm} \mathrm{CW})$ weighs approximately $110 \mathrm{~g}$ (Guillory et al. 2001). By multiplication, annual recruitment to the Gulf-wide stock would be $1 \times 10^{5}$ tons, approximately the upper bound of our independent estimates of the stock from fishery data (0.4-1.0 × $10^{5}$ tons $)$.

\section{Blue crab population model}

Gulf-wide hard crab landings increased linearly over the historical time series (Fig. 3). A linear increasing trend in fishery-independent total mortality that correlated strongly with landings
(Fig. 4) and a linear decreasing trend in CPE (Fig. 5) provided independent evidence to support our assumption that the trend in landings was largely the result of increasing fishing mortality. The fishable stock, estimated from reported landings and $U$, was dynamically stable over the 1950-2004 time series.

Estimated recruitment to the fishable stock showed large interannual variation, but no apparent trend (Fig. 6). Our estimation process attributed all of the interannual variation in landings to recruitment, after removing the long-term trend. Large-scale environmental variation, including total annual precipitation for the Gulf states, mean and peak Mississippi River discharge, and hurricane frequency and intensity, were not significantly correlated with variation in recruitment.

A hindcast simulation matched the trend in reported landings (Fig. 7, Table 3). Forecast scenarios all predicted declining stock and landings (Fig. 8). The 
Fig. 4. Catch per effort for hard crabs in the Gulf of Mexico blue crab trap fishery by year. The linear trend was estimated using linear regression: $y=-0.00175 x+3.54$, where $y$ is the catch per effort (tons/ trap) and $x$ is the year; $\mathrm{R}^{2}=0.57, \mathrm{p}=0.0002$.

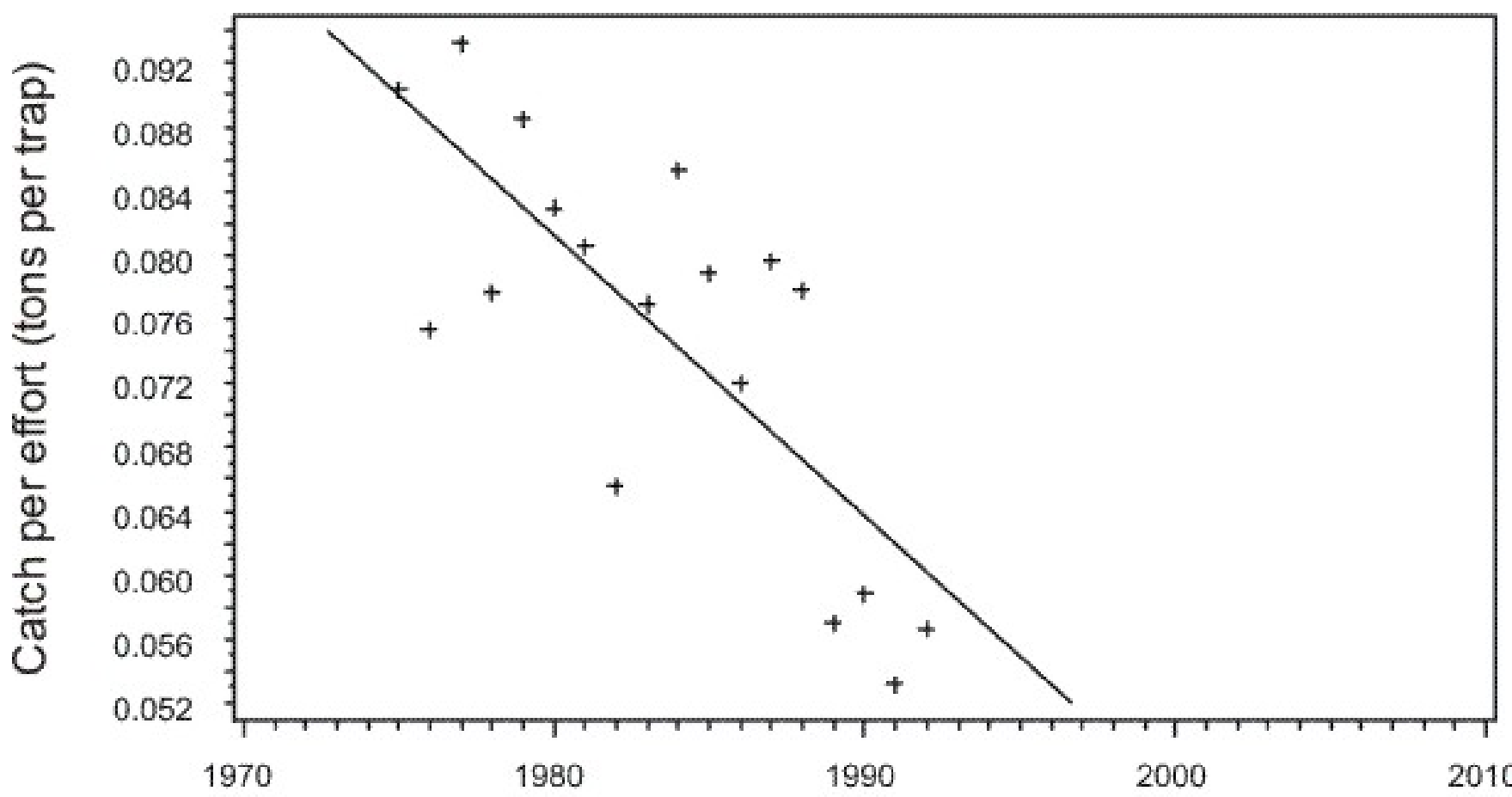

Year

baseline (no future habitat alteration) rate of population change $(r)$ was slightly negative and predicted a modest decline in stock and landings. Considering that this negative value of $r$ could be an artifact of the estimation process, we simulated an alternative baseline scenario with $r$ set to zero (Table 4). In the altered habitat simulations, $r$ had larger negative values than the baseline and was more negative for hardened shoreline than for seagrass loss. Stochastic variation in $r$ resulted in wide dispersion of model predictions, with approximately log-normal distributions of means over iterative model runs. Although the mean predictions for the scenarios differed substantially, the bootstrap standard errors overlapped, so mean predictions did not differ significantly in the statistical sense (Table 5).

Another way to gauge uncertainty in forecasting models is to estimate the probability of an expected or desired outcome (e.g., Jordan and Coakley 2004). In the model discussed here, these probabilities were directly proportional to the value of $r$. With $r$ set to zero, the probability was $54 \%$ that landings in 2050 would equal or exceed the 2004 quantity. Positive values of $r$ would generate higher probabilities, and negative values would generate lower probabilities. For the same criterion, the baseline scenario suggested a probability of $39 \%$, the $20 \%$ baywide SAV loss scenario $26 \%$, the SAV loss in one hexagon scenario 35\%, and the $10 \%$ hardened shoreline scenario 4\% (Fig. 9). In other words, if sustainability at the 2004 level were a goal for the blue crab fishery, the baywide SAV loss scenario predicts a $74 \%$ chance of failure, and the hardened shoreline scenario a $96 \%$ chance of failure. 
Fig. 5. Fishery-independent estimates of total mortality as a function of blue crab landings in the trap fishery, with the linear trend. The linear trend was modeled using linear regression: $y=1.621 \times 10^{-5} x+$ $0.55 ; \mathrm{R}^{2}=0.56, \mathrm{p}<0.0001$.

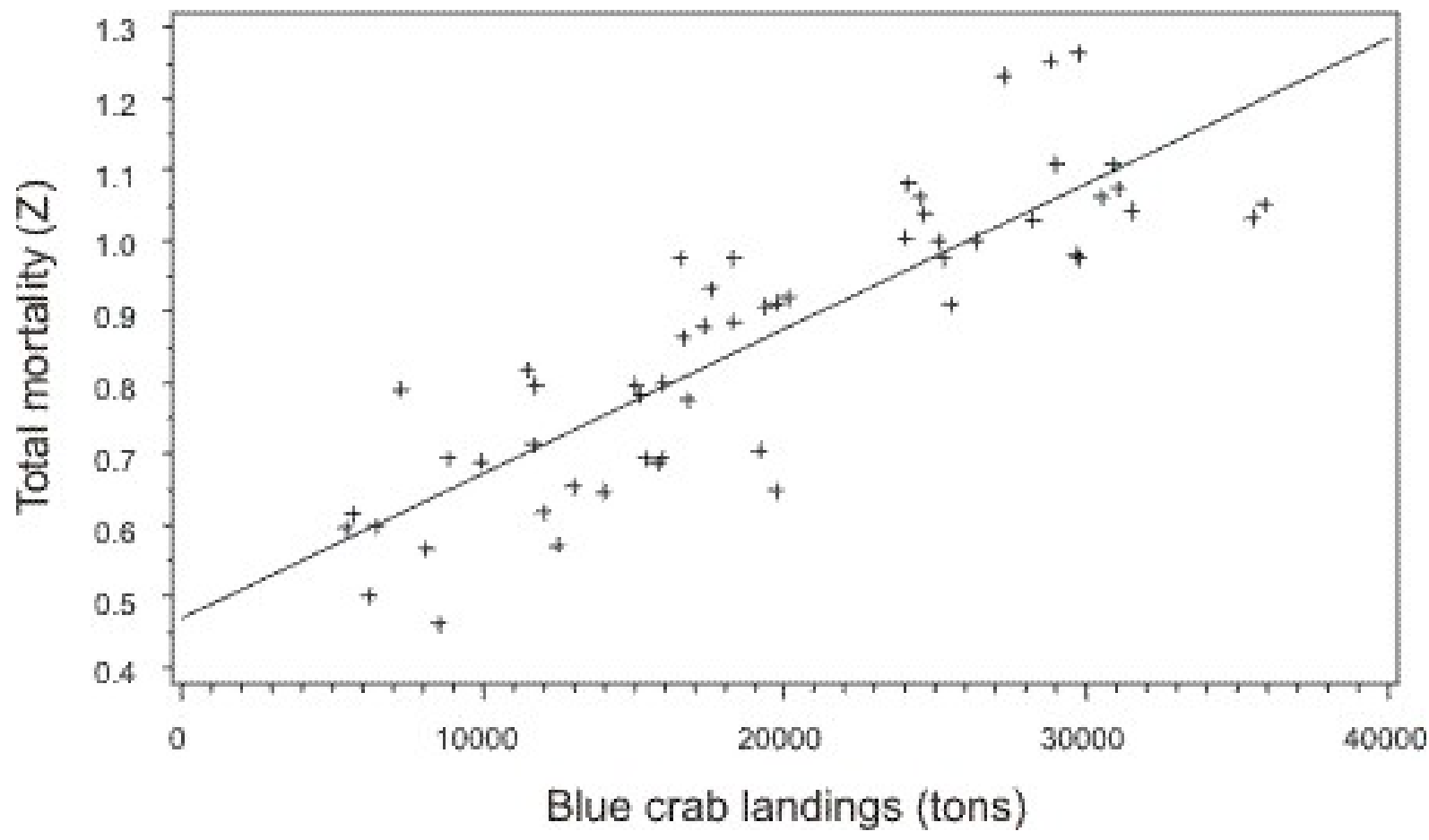

\section{DISCUSSION}

Our goal was to develop a modeling framework for studies of cumulative effects of habitat alteration on fishery resources at region-wide and smaller scales. This study was an opportunity to explore sources of data, identify major elements of uncertainty and data gaps, and demonstrate the concept of linking population processes and responses to stressors across geographic scales (Munns 2006). We have demonstrated a workable approach to the problem of linking habitat effects at patch scales to largescale population processes. Moreover, this multiscale modeling approach suggests the feasibility of predicting cumulative effects of habitat alteration on valuable ecological goods such as fisheries and services such as biotic productivity.

There were uncertainties associated with each spatial scale of our analysis and each source of data. Errors in the land-cover and seagrass coverage data were probably minor compared to other sources of uncertainty, but the data were point-in-time estimates. Assuming that we could account accurately for anthropogenic changes in habitat characteristics, natural temporal variation in these spatial patterns could introduce significant uncertainties into long-term predictions. The model is sensitive to marginal changes in the areal distribution of habitat types (Fig. 8). At the patch scale, we used mean values for blue crab density and survival, ignoring any variability in the estimates. Although small-scale variation in these properties could be large, we expect the estimates to be relatively robust at larger scales. In studying habitat selection by the blue crab, Meise and Stehlik (2003) suggested that habitat factors that appeared to be significant at fine temporal scales, e.g., seasons, might not be significant at larger scales, e. g., years. The same principle may apply to spatial scales, suggesting that cumulative effects of habitat alterations over large spans of space and time may be more important to the sustainability of habitatdependent populations than variations at within- 
Fig. 6. Detrended blue crab landings for 1950-2004.

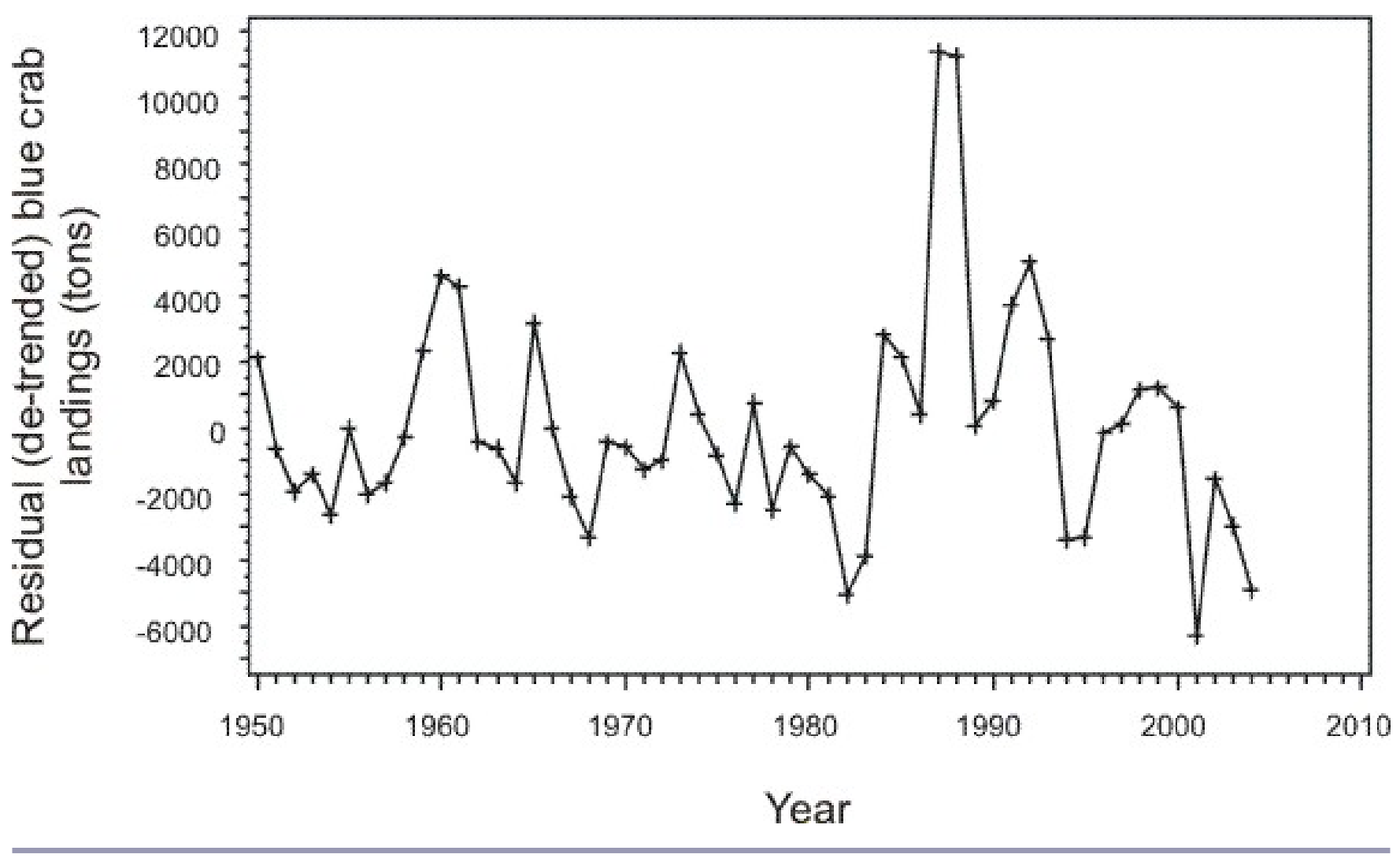

patch or between-patch scales. A sensitivity analysis indicated that the model is robust to fairly large systematic errors in density and early life stage survival estimates. Increases or decreases of $50 \%$ in either or both estimates would not change the results qualitatively, although absolute values of $r$ computed from 50\% increases in density and survival appear unreasonably large.

At the whole-estuary scale, we used a mean value derived from the literature for pre-recruit survival $S_{2}$. The current model formulation is not sensitive to this constant; only the proportional reduction in numbers and survival of smaller crabs based on habitat quantity and quality ( $D$ and $S_{1}$ ) affects the fishery model. Nevertheless, it is encouraging for future studies that independent estimates of prerecruit survival from Alabama and Mississippi were equivalent. A more detailed model would benefit from large-scale validation of these estimates and their variability for Gulf of Mexico estuaries or relevant classes of estuaries (Engle et al. 2007). We extrapolated habitat effects on recruitment from Mobile Bay to the U.S. Gulf-wide crab stock, thereby introducing potentially large uncertainty. Some lines of evidence suggest, however, that the uncertainty may not be great. First, our long-term estimates of recruitment were derived from the region-wide fishery, so there was no spatial extrapolation involved in estimating the baseline value of $r$ or its variability. Second, the absolute magnitude of modeled recruitment from the Mobile Bay system was consistent with, although somewhat larger than, our fishery-dependent estimates of Gulf-wide stock size. A higher estimate of stock size from fishery-independent data is to be expected because we used only hard crab landings for the fishery-independent estimate; portions of the stock are harvested in other fisheries, and a portion may not be vulnerable to fishing because of habitat refuges or for other reasons. Third, although variable, the available data for densities and early 
Fig. 7. Model hindcast simulation of Gulf of Mexico blue crab landings.

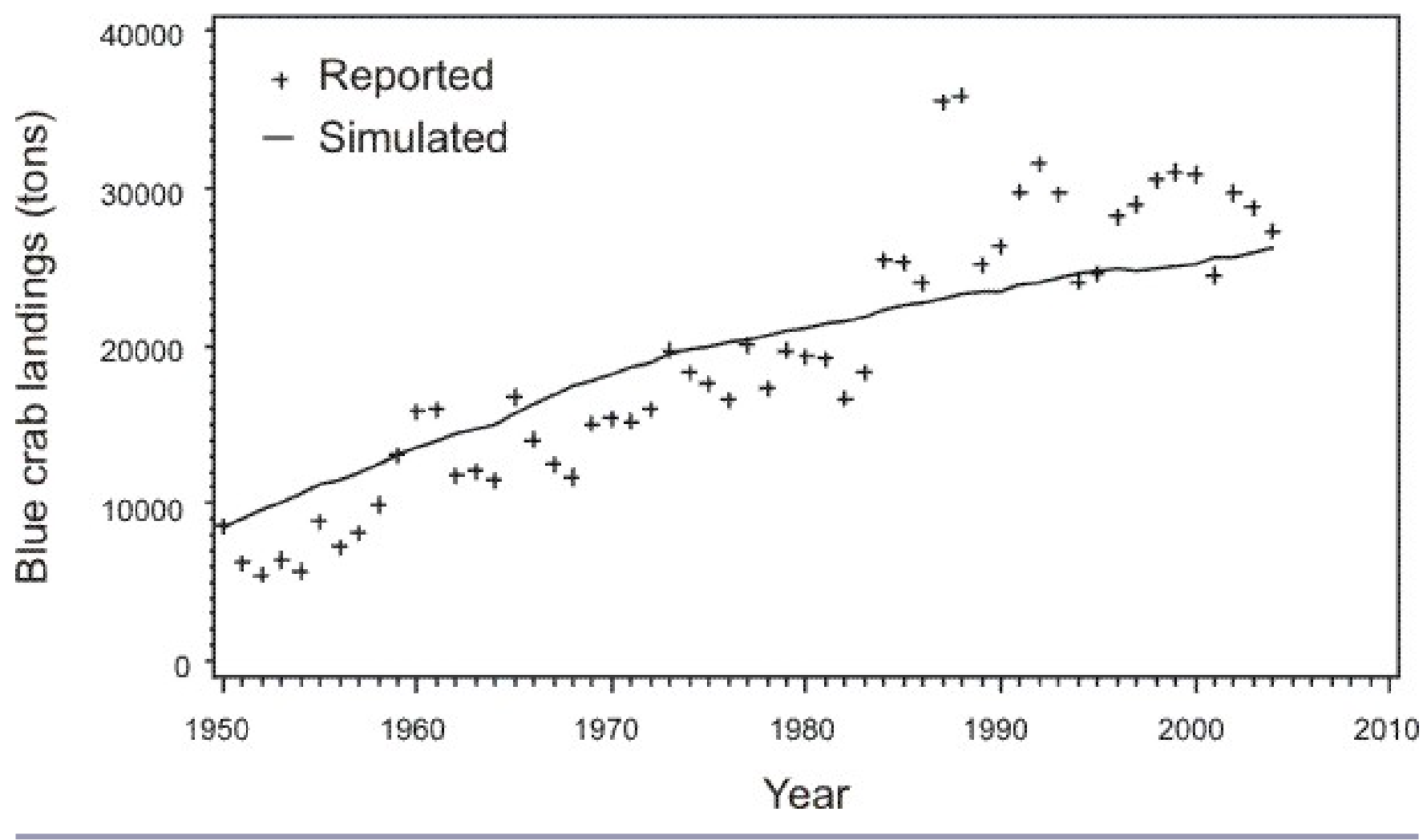

juvenile survival rates from several Gulf of Mexico and Atlantic coast estuaries showed consistent patterns across the three habitat types simulated in the model. If the values that we used are representative, as the evidence from these three lines of verification indicates, then the model should be accurate.

The fishery population model includes several uncertainty factors, the largest of which is the stochastic interannual variation in apparent recruitment. This is the only source of model variation that we have quantified in the model results. Although we do not expect to explain all of the variability in recruitment, there are two approaches that might reduce the uncertainty in this parameter. The first is to refine the modeling of recruitment processes, for example, by using matrix-based life-history modeling (e.g., Miller 2001) at appropriate spatial scales to investigate sources of variability in the recruitment process. The second is to investigate environmental correlations with the long-term recruitment time series. Where many years of data are available for parameterizing models, as in the case of the blue crab fishery, the influence of interannual and decadal environmental variation is implicit and may be partially quantifiable through correlations with environmental variables. Therefore, it is surprising that there were no significant correlations of recruitment $(0-3-\mathrm{yr}$ lags) with large-scale environmental variation, including annual precipitation, the frequency and intensity of Gulf of Mexico hurricanes, and annual mean and peak Mississippi River discharge. Other attempts to explain recruitment variability in blue crab populations with environmental variables have been unsatisfying (Fogarty and Lipcius 2007).

A final concern with the fishery model is the implicit stock-recruitment relationship. With the exponential formulation used here, the number of recruits increases or decreases linearly with stock size, leading to a compounding effect over years that is observed in the forward simulations. The density- 
Fig. 8. Simulated blue crab landings based on five scenarios. SAV = shoreline aquatic vegetation. See Methods: Mobile Bay recruitment analysis for an explanation of the scenarios.

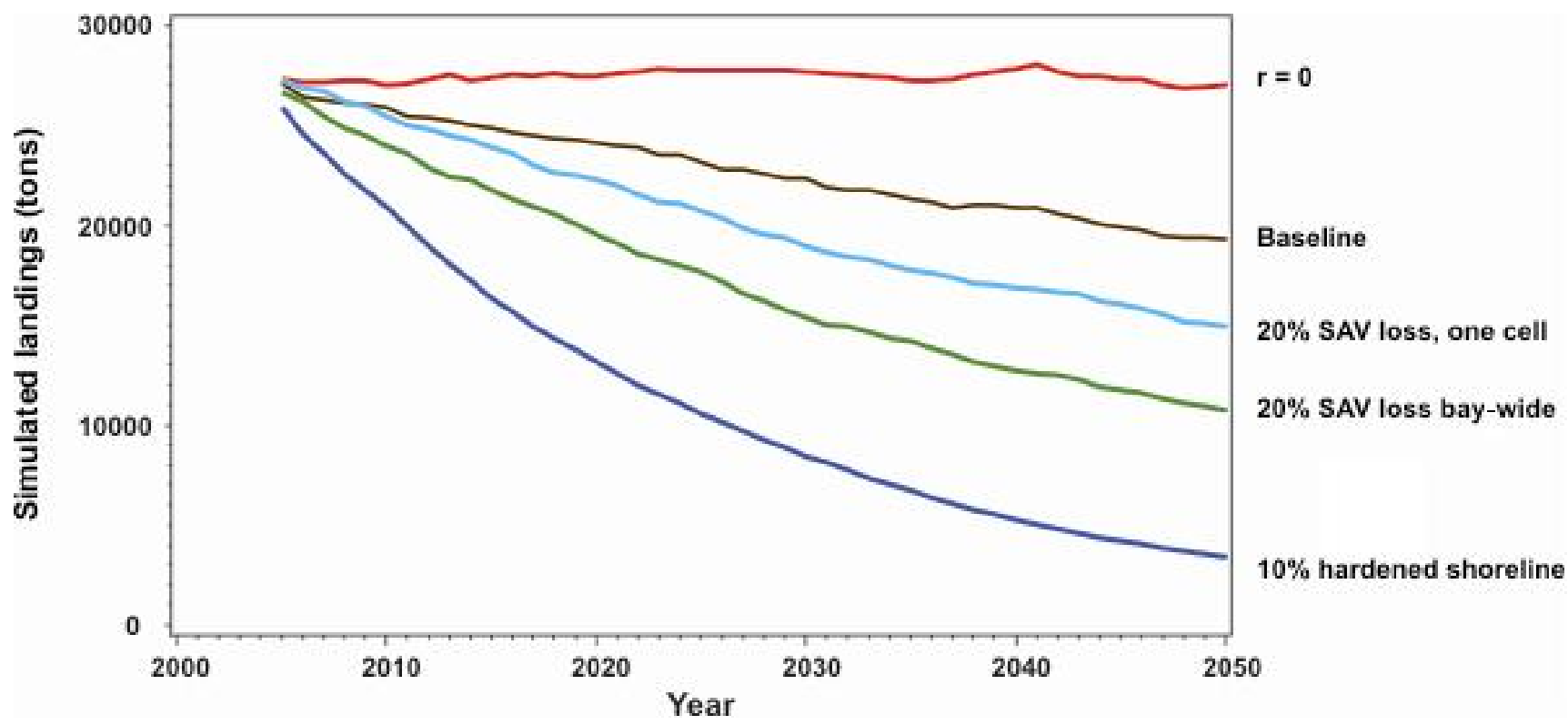

dependent models often used in fisheries science and management generally predict reduced recruitment at high stock levels, with maximum recruitment from stocks at intermediate or relatively low levels. Kahn et al. (1998), in a comprehensive analysis and discussion of the stock-recruitment relationship for blue crab in Delaware Bay, demonstrated apparently density-dependent patterns in indices of stock and recruitment, but could not rule out a linear model. Guillory et al. (2001), in their comprehensive review of the fishery and population, could not establish a stock-recruitment relationship for Gulf of Mexico blue crab. The question for our model applies only to the relationship between the adult stock and subsequent recruitment to the adult stock. Well-established density-dependent processes such as cannibalism of small juvenile crabs by larger pre-recruits, densitydependent predation, and other processes that operate between and among early life stages (Heck and Spitzer 2001) would be implicit in the density and survival estimates used in our recruitment model. We found no correlations between the model $r$ parameter and independent estimates of Gulf-wide total mortality or catch per effort (Guillory et al.
2001) that might have suggested density-dependent recruitment. Estimates in our model of annual stock size and recruitment were not independent, so they could not be used to investigate density dependence. To our knowledge, there are no other time-series estimates of the Gulf of Mexico blue crab stock with which we could compare our recruitment estimates.

We suggest that over long periods of time, stock size may be linearly related to recruitment in a probabilistic sense. With a stock that is well below carrying capacity, as appears to be the case for the Gulf of Mexico stock because of exploitation, the magnitude of recruitment is likely to be larger with a larger stock size and smaller with a smaller stock size. This dynamic is embedded within the large year-to-year stochastic variation in recruitment, which also obscures any stock-recruitment relationship. Compensation no doubt occurs in the blue crab, as in virtually all animal populations, but it could not be observed using our data and methods. The linear stock-recruitment relationship could cause this model to overpredict stock and harvest declines caused by chronic stressors such as habitat loss. For this reason, the model is conservative with 
Table 4. Values of variables and parameters used to simulate blue crab stock and landings for forecast scenarios.

\begin{tabular}{lcc}
\hline \hline \multicolumn{1}{c}{ Variable or parameter } & Value (units) & Standard deviation \\
\hline Year & $2005-2050$ & \\
Initial stock & 54,640 (tons) & \\
Instantaneous annual rate of fishing mortality, $F$ & 0.692 & 0.176 \\
$r \dagger$ for baseline scenario & -0.0083 & 0.176 \\
$r$ for 20\% loss of shoreline aquatic vegetation bay-wide & -0.019 & 0.176 \\
scenario & & \\
$r$ for 20\% loss of shoreline aquatic vegetation, 1 cell & -0.012 & 0.176 \\
scenario & -0.045 & \\
$r$ for 10\% hardened shoreline scenario & & \\
\hline
\end{tabular}

$\dagger r=$ rate of population change.

respect to sustaining the resource; the risk to the fishery and the ecosystem is in underprediction. This principle also would apply in managing a fishery; density-dependent models predict maximum production (i.e., maximum sustainable yield) at relatively low stock levels, thereby encouraging high fishing mortality rates and increased risk of recruitment overfishing and stock collapse (Larkin 1977).

Our model uses observed densities of juvenile blue crab in selected habitat types to estimate recruitment to the Gulf of Mexico harvestable stock. By varying the areal extent of habitat types, we project future stock size and landings based on the quantification of historical stock and recruitment. The model indicates that the conversion of the preferred habitat types of seagrass beds and marsh edges to less ecologically beneficial types could have negative effects on the valuable blue crab fishery of the northern Gulf of Mexico. In an extensive study of nekton use of Mississippi coastal habitats, Peterson et al. (2000) found reduced densities of blue crab and several other estuarine species in locations where marsh habitats had been altered by development. Many other studies have obtained similar results (e.g., Able et al. 1998, Carroll 2002), but differences in relative or absolute densities are less certain indicators of habitat effects than habitatspecific observations of critical population parameters, especially survival and growth rates, which are far more difficult to obtain than densities. It is also possible that losses of shallow-water vegetated habitats could be compensated by alternative structurally complex habitats, e.g., oyster reefs and artificial reefs. The improvement of models of habitat effects will require knowledge about whether certain habitat types are essential to recruitment or merely preferred by the organism of interest. The combination of habitat-specific densities and survival rates used to estimate habitat effects in our recruitment analysis partially satisfies this requirement.

Modeling across spatial scales from the local to the global is essential to achieve a better understanding of ecosystem services and the policies and management measures required to maintain them or restore those that have been lost and degraded (Carpenter et al. 2006). The full realization of multiscale models of the type presented here will benefit from complete, higher-resolution, digital spatial coverage of coastal habitats. These are currently under development, for example, under the habitat characterization priority of the Gulf of Mexico Alliance (2006). Models that link the 
Table 5. Summary statistics for modeled scenarios of the effects of habitat change on Gulf of Mexico blue crab landings. Means are for the last five years of simulations, with 1000 iterations/yr $(N=5000)$. Statistics are back-transformed from approximately log-normal distributions, i.e., geometric means and errors. SE $=$ bootstrap standard error of the mean.

\begin{tabular}{lccc}
\hline \hline Scenario & Mean (tons) & $-1 \mathrm{SE}$ & $+1 \mathrm{SE}$ \\
\hline$r_{\dagger}^{\dagger}=0$ & 27,311 & 8770 & 85,054 \\
Baseline & 18,638 & 5782 & 60,073 \\
$20 \%$ loss of shoreline aquatic vegetation & 11,337 & 3512 & 36,602 \\
$20 \%$ loss of shoreline aquatic vegetation, one cell & 33,332 & 5209 & 52,885 \\
$10 \%$ hardened shoreline & 3955 & 1226 & 12,756 \\
\hline
\end{tabular}

$\dagger r=$ rate of population change. 
Fig. 9. Probabilities of attaining 2004 levels of blue crab harvest in 2046-2050 based on five modeled scenarios of habitat loss. $\mathrm{SAV}=$ shoreline aquatic vegetation.

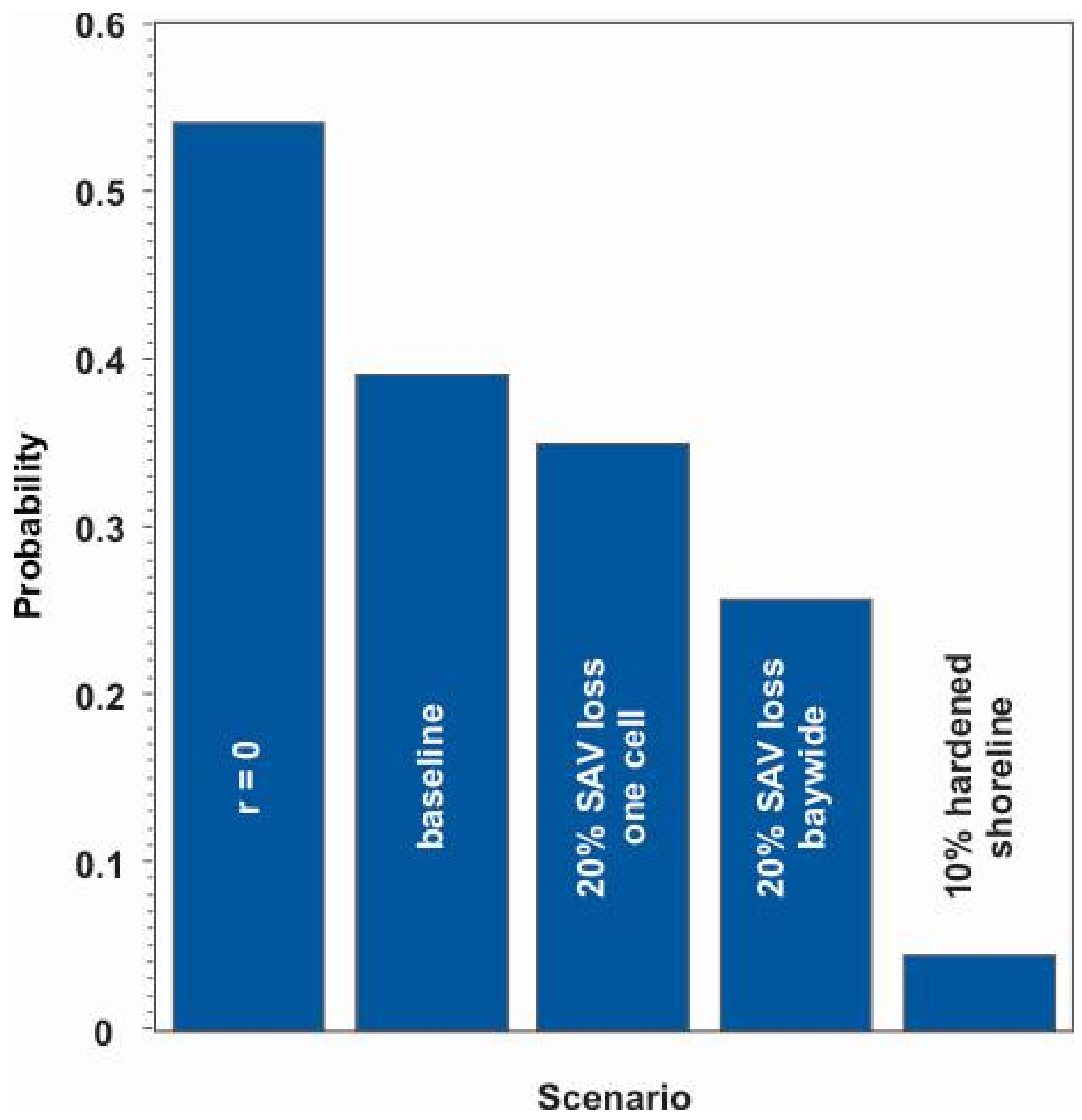


structural and functional properties of habitats to populations and their values are both promising and essential (Sanchirico and Mumby 2007).

Our simulations suggest that direct annual losses to the U.S. Gulf of Mexico blue crab fishery could be on the order of US \$10-20 million (dockside value) per year, based on 1995-2004 prices. Long-term ecological effects also would be significant. The blue crab is ubiquitous and abundant in estuaries of the southeastern U.S. and occupies a central position in estuarine food webs (Baird and Ulanowicz 1989). Our results suggest that the potential risk, not only for blue crab, but also for other ecologically and economically valuable species, demands further investigation.

Responses to this article can be read online at: http://www.ecologyandsociety.org/voll4/iss1/art16/ responses/

\section{Acknowledgments:}

We thank Sandy Raimondo, Kevin Summers, and two anonymous reviewers for valuable, constructive suggestions, and Syma Ebbin for a helpful preliminary review. Pete Bourgeois (USGS) provided land-cover calculations and mapping. Virginia Engle assisted in obtaining the precipitation data. The information in this document has been funded wholly (or in part) by the U.S. Environmental Protection Agency. It has been subjected to review by the National Health and Environmental Effects Research Laboratory and approved for publication. Approval does not signify that the contents reflect the views of the Agency, nor does the mention of trade names or commercial products constitute endorsement or recommendation for use. This is contribution number 1284 from the Gulf Ecology Division.

\section{LITERATURE CITED}

Able, K. W., J. P. Manderson, and A. L. Studholme. 1998. The distribution of shallow water juvenile fishes in an urban estuary: the effects of manmade structures in the lower Hudson River. Estuaries 21(4):731-744.
Baird, D., and R. E. Ulanowicz. 1989. The seasonal dynamics of the Chesapeake Bay ecosystem. Ecological Monographs 59(4):329-364.

Barry A. Vittor and Associates, Inc. 2004. Mapping of submerged aquatic vegetation in Mobile Bay and adjacent waters of coastal Alabama in 2002. Report prepared for the Mobile Bay National Estuary Program, Mobile, Alabama, USA.

Carpenter, S. R., R. DeFries, T. Dietz, H. A. Mooney, S. Polasky, W. V. Reid, and R. J. Scholes. 2006. Millennium ecosystem assessment: research needs. Science 314:257-258.

Carroll, R. A. 2002. Nekton utilization of intertidal fringing salt marsh and revetment hardened shorelines. Thesis. College of William and Mary, Williamsburg, Virginia, USA.

Cato, J. C., and C. M. Adams. 1999. Economic significance of the Gulf of Mexico related to population, income, employment, minerals, fisheries, and shipping. Pages 14-33 in H. Kumpf, K. A. Steidinger, and K. Sherman, editors. The Gulf of Mexico large marine ecosystem: assessment, sustainability, and management. Blackwell, Malden, Massachusetts, USA.

Dantin, D. D., W. S. Fisher, S. J. Jordan, and J. T. Winstead. 2005. Fishery resources and threatened coastal habitats in the Gulf of Mexico. U.S. Environmental Protection Agency report EPA/600/R-05/051. Gulf Breeze, Florida, USA.

Engle, V. D., J. C. Kurtz, L. M. Smith, C. Chancy, and P. Bourgeois. 2007. A classification of U.S. estuaries based on physical and hydrologic attributes. Environmental Monitoring and Assessment 129(1-3):397-412.

Fogarty, M. J., and R. N. Lipcius. 2007. Population dynamics and fisheries. Pages 711-755 in V. S. Kennedy and L. E. Cronin, editors. The blue $c r a b$ Callinectes sapidus. Maryland Sea Grant, College Park, Maryland, USA.

Guillory, V., H. Perry, P. Steele, T. Wagner, P. Hammerschmidt, S. Heath, and C. Moss. 1998. The Gulf of Mexico blue crab fishery: historical trends, status, management, and recommendations. Journal of Shellfish Research 17(2):395-403.

Guillory, V., H. Perry, P. Steele, T. Wagner, W. 
Keithly, B. Pellegrin, J. Petterson, T. Floyd, B. Buckson, L. Hartman, E. Holder, and C. Moss. 2001. The blue crab fishery of the Gulf of Mexico, United States: a regional management plan. Publication number 96. Gulf States Marine Fisheries Commission, Ocean Springs, Mississippi, USA. Available online at: http://www.gsmfc.org/pu blications/GSMFC\%20Number\%20096.pdf.

Gulf of Mexico Alliance. 2006. Governor's action plan for healthy and resilient coasts. Available online at: http://www.gulfofmexicoalliance.org/pdfs/ gulfactionplan final.pdf.

Heath, S. R. 1998. The Alabama blue crab fishery: historical trends, status, management, and the future. Journal of Shellfish Research 17 (2):435-439.

Heck, Jr., K. L., L. D. Coen, and S. G. Morgan. 2001. Pre- and post-settlement factors as determinants of juvenile blue crab Callinectes sapidus abundance: results from the north-central Gulf of Mexico. Marine Ecology Progress Series 222:163-176.

Heck, Jr., K. L., and P. M. Spitzer. 2001. Post settlement mortality of juvenile blue crabs: patterns and processes. Pages 18-27 in V. Guillory, H. Perry, and S. VanderKooy, editors. Proceedings of the Blue Crab Mortality Symposium (Lafayette, Louisiana, 1999). Gulf States Marine Fisheries Commission, Ocean Springs, Mississippi, USA.

Jordan, S. J., and J. M. Coakley. 2004. Long-term projections of eastern oyster populations under various management scenarios. Journal of Shellfish Research 23(1):63-72.

Kahn, D. M., R. W. Cole, S. F. Michels, and W. H. Whitmore. 1998. Development of life-stage specific indices of relative abundance and stockrecruitment relationships for the Delaware Bay blue crab stock. Journal of Shellfish Research 17 (2):529-541.

Larkin, P. A. 1977. An epitaph for the concept of maximum sustained yield. Transactions of the American Fisheries Society 106(1):1-11.

McMillen-Jackson, A. L., T. M. Bert, and P. Steele. 1994. Population genetics of the blue crab Callinectes sapidus: modest population structuring in a background of high gene flow. Marine Biology 118(1):53-65.

Meise, C. J., and L. L. Stehlik. 2003. Habitat use, temporal abundance variability, and diet of blue crabs from a New Jersey estuarine system. Estuaries 26(3):731-745.

Miller, T. J. 2001. Matrix-based modeling of blue crab population dynamics with applications to the Chesapeake Bay. Estuaries 24(4):535-544.

Minello, T. J. 1999. Nekton densities in shallow estuarine habitats of Texas and Louisiana and the identification of essential fish habitat. American Fisheries Society Symposium 22:43-75.

Minello, T. J., K. W. Able, M. P. Weinstein, and C. G. Hays. 2003. Salt marshes as nurseries for nekton: testing hypotheses on density, growth and survival through meta-analysis. Marine Ecology Progress Series 246:39-59.

Moksnes, P.-O., R. N. Lipcius, L. Pihl, and J. van Montfrans. 1997. Cannibal-prey dynamics in young juveniles and postlarvae of the blue crab. Journal of Experimental Marine Biology and Ecology 215(2):157-187.

Munns, Jr., W. R. 2006. Assessing risks to wildlife populations from multiple stressors: overview of the problem and research needs. Ecology and Society 11(1): 23. [online] URL: http://www.ecologyandso ciety.org/vol11/iss1/art23/.

Pellegrin, Jr., G., V. Guillory, P. Prejean, H. Perry, J. Warren, P. Steele, T. Wagner, and S. Heath. 2001. Length-based estimates of total mortality for Gulf of Mexico blue crab. Pages 42-49 in V. Guillory, H. Perry, and S. VanderKooy, editors. Proceedings of the Blue Crab Mortality Symposium (Lafayette, Louisiana, 1999). Gulf States Marine Fisheries Commission, Ocean Springs, Mississippi, USA.

Perry, H. M., J. Warren, C. Trigg, and T. Van Devender. 1998. The blue crab fishery of Mississippi. Journal of Shellfish Research 17 (2):425-433.

Peterson, M. S., B. H. Comyns, J. R. Hendon, P. J. Bond, and G.A. Duff. 2000. Habitat use by early life-history stages of fishes and crustaceans along a changing estuarine landscape: differences between 
natural and altered shoreline sites. Wetlands Ecology and Management 8(2-3):209-219.

Sanchirico, J. N., and P. Mumby. 2007. Economics, habitats, and biological populations: finding the right value. Resources 165:11-13.

Scavia, D., J. C. Field, and D. F. Boesch. 2003. Forecasting climate impacts on coastal ecosystems. Pages 23-28 in N. J. Valette-Silver and D. Scavia, editors. Ecological forecasting: new tools for coastal and ecosystem management. National Oceanic and Atmospheric Administration Technical Memorandum NOS-NCCOS-1. National Oceanic and Atmospheric Administration, Washington, D. C., USA.

U.S. Environmental Protection Agency. 2005. National coastal condition report II. U.S. Environmental Protection Agency, Washington, D. C., USA. Available online at: http://www.epa.gov/ owow/oceans/nccr/2005/index.html. 